\title{
Thomas Marthaler: Scientist, Musician, Friend
}

It is a privilege to be able to say a word about our dear friend and colleague "Tomi" Marthaler, who died on the 13th of November 2020, aged 91.

Tomi was a giant in the world of caries prevention and there were several stages to his long career. He served as a dentist at his father's practice and, while working parttime at Zurich's Dental Institute, he studied the effect of fluoride on dental caries in rodents. He was awarded a Doctorate by the University of Zurich and carried out longitudinal studies on schoolchildren and clinical trials in caries prevention. These interests led to his serious involvement with mathematics and statistics. He became Head of Zurich University's Biostatistical Centre and served as an adviser to the WHO. Through his support for the fluoridation of salt, some of the benefits of his lifelong endeavours in caries prevention have been passed on to his fellow citizens in Switzerland.

His enormous contributions to the field of epidemiology and dental caries have been recognised and variously honoured in Europe, Scandinavia, and elsewhere. Much of Tomi's work has been described in over 300 scientific papers. In 2010 he was acclaimed as "Dentist of the Year" by the Academy of Dentistry International in the USA.

Tomi had another life. In celebration of his 80th birthday, Prof. Imfeld referred to Tomi's "dental probe and clarinet." Many of us on the periphery of Tomi's statisti-

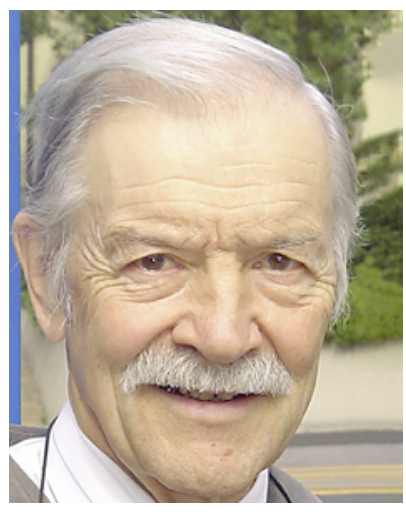

Thomas Marthaler

cal kingdom found the clarinet much more musical than the probe. Tomi had another name in Switzerland, where, under the alias "Sabu," he wrote music. At Zurich's Amateur Jazz Festival, his group once shared the honour of third place with the Porridge Brass Band.

Several of us, who are approaching or share with Tomi the title of "nonagenarian," have lost a warm and valued friend. Our love and heartfelt condolences go to all of Tomi's family and our dear friend, Tomi's wife, Marianne. Prof. em. Klaus König, University of Nijmegen Prof. em. Walter Künzel, University of Erfurt Prof. em. John Weatherell, University of Leeds 